\title{
Ferrite Formation Characteristics in Si-Mn TRIP Steels
}

\author{
A. ZAREI-HANZAKI and S. YUE ${ }^{1)}$
}

Department of Metallurgy and Materials Science, Faculty of Engineering, Tehran University, P.O. Box 14395/551 Tehran, Iran. 1) Department of Mining and Metallurgical Engineering, McGill University, 3450 University Street, Montreal, PO, H3A 2A7 Canada.E-mail: Steve@Minmet.Lan.McGill.CA

(Received on September 9, 1996; accepted in final form on March 7, 1997)

\begin{abstract}
If the austenite-to-proeutectoid ferrite reaction is the first phase transformation which occurs during cooling of a hypoeutectoid steel, growth of ferrite takes place by rejection of carbon into the untransformed austenite, such that the carbon content of the austenite increases with increasing ferrite volume fraction. The carbon enrichment of austenite affects the state of retained austenite in the final microstructure. Such an effect is important when designing microstructures of transformation induced plasticity (TRIP) steels, which are a new class of high formable steels. These grades of TRIP steels, which are in excess of Si and $\mathrm{Mn}$, make use of ferrite and bainite as the major micro-components. This work details the results of a systematic investigation on the ferrite formation characteristics and their effects on the state of the retained austenite. The results showed that the retained austenite volume fraction increases with the amount of ferrite and, after a plateau, decreases. Furthermore, the presence of acicular ferrite resulted in a significant increase in the quantity of the retained austenite.
\end{abstract}

KEY WORDS: ferrite; bainite; retained austenite; TRIP steels; thermomechanical processing (TMP); hot rolling of steels; dynamic transformation.

\section{Introduction}

The optimization of strength, ductility and toughness of metals and alloys may be achieved by alloying, in conjunction with heat treatment or thermomechanical processing. Various types of compositions and heat treatments have been used to improve such properties in steels. Strength and ductility are of primary interest among the steel users, especially in automotive industries, where safety and fuel efficiency can be improved by reducing vehicle weight. ${ }^{1)}$ It is well known that the strain or stress induced transformation of retained austenite to martensite can significantly strengthen the deforming steel and therefore result in higher ductility. This is the principle of transformation induced plasticity (TRIP), as originally discovered by Zackay et $a .^{2)}$ The presence of retained austenite in the microstructure also results in higher toughness through localized TRIP leading to crack tip blunting. ${ }^{3)}$

Employing the TRIP phenomenon to produce steels with higher strength without loss of formability resulted in the development of a new class of steels which have relatively high levels of $\mathrm{Si}$ and $\mathrm{Mn}$. The majority of the studies, concerning $\mathrm{Si}(1-2 \%)-\mathrm{Mn}(1-2 \%)$ steels, have capitalised on the benefits of proeutectoid ferrite and bainite in the microstructure. The present study concerns the control of the microstructure by thermomechanical processing (TMP) in order to attain the optimum conditions (size, distribution, quantity, composition and morphology) of retained austenite in Si-Mn TRIP steels.
The ultimate goal is to identify thermomechanical processing strategies to optimise TRIP behaviour in the ashot rolled condition. In this paper, the ferrite formation characteristics and their effect on the state of the retained austenite are investigated.

\section{Experimental Procedure}

The steels which were investigated in this work (Table 1), were received in the as-hot rolled condition, from which specimens were machined. These steels have more or less the same chemical composition, the only difference being $\mathrm{Nb}$. The silicon levels in these steels are almost four or five times greater than conventional or mild steels. The presence of $\mathrm{Nb}$ in steel $\mathrm{A}$ raises the austenite no-recrystallization temperature and, for certain TMP schedules, results in "pancaked" (i.e., severely deformed) austenite grains.

For the purpose of designing TMP schedules, knowledge of three critical temperatures is required. These are the $T_{\mathrm{nr}}, \mathrm{Ar}_{3}$ and $\mathrm{Ar}_{1}$, which are the no-recrystallization temperature, and the start and finish temperatures of the austenite-to-ferrite transformation, respectively. These temperatures were measured by CCC (Continuous Cooling Compression) testing. ${ }^{4,5}$

Table 1. Chemical compositions of experimental steels.

\begin{tabular}{||c|c|c|c|c|c|c||}
\hline Composition & $C \%$ & Si\% & $M n \%$ & $N b \%$ & $A l \%$ & $N(p p m)$ \\
\hline Steel A (Nb-steel) & 0.22 & 1.55 & 1.55 & 0.035 & 0.028 & $20-40$ \\
\hline Steel B (Reference-steel) & 0.19 & 1.50 & 1.54 & - & 0.024 & $20-40$ \\
\hline
\end{tabular}


The steels were also subjected to various hot deformation tests, all of which were performed using a computerized materials testing system adapted for hot deformation tests. ${ }^{4)}$ Figure 1 shows the thermal and deformation schedules which were applied to generate different conditions of ferrite formation. As can be seen, after solutionizing (which was performed to dissolve any $\mathrm{Nb}(\mathrm{CN})$ and $\mathrm{AlN}$ precipitates present in the initial microstructure), the specimen was cooled down to a typical industrial TMP temperature. A series of deformations was applied at this temperature to obtain different austenite grain sizes. The specimen was then cooled down to a temperature below the $\mathrm{Ar}_{3}$ and then held isothermally to form a known volume fraction of polygonal ferrite. This was followed by a salt bath quench, where the specimen was held isothermally for a predetermined duration at $400^{\circ} \mathrm{C}$, to transform the austenite to bainite (this temperature was expected to maximize the retained austenite volume fraction, according to the literature ${ }^{6}$ ). The specimen was then air cooled to room temperature.

The retained austenite measurements were performed by X-ray diffraction. ${ }^{7)}$ The subsequent analysis was performed based on the integrated intensities of (111), (200), (220) and (113) austenite peaks, and (110), (200) and (112) ferrite lines. In the retained austenite quantity calculations, attempts have been made to consider the presence of the probable preferred orientation in the microstructure by using appropriate relationships. ${ }^{8)}$

\section{Results and Discussion}

\subsection{The Austenite-to-Ferrite Transformation Character- istics}

The CCC test not only generated all the three critical

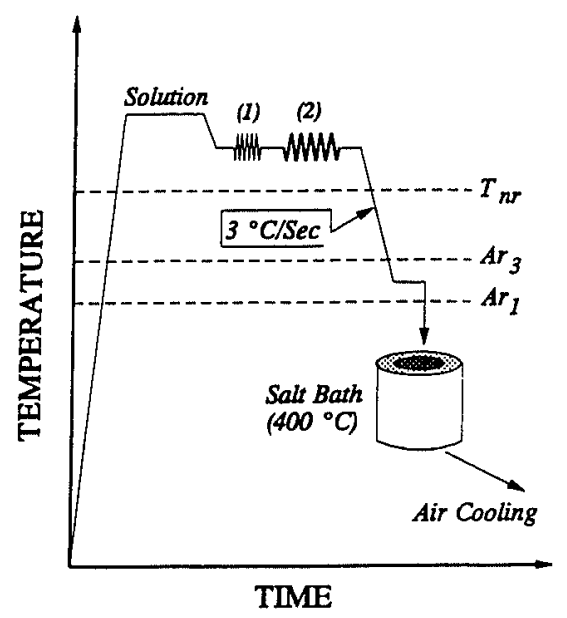

Fig. 1. Schematic diagram of heat and deformation schedule. temperatures for TMP schedule design (Table 2), but also revealed other transformation characteristics. The isothermal transformation rate of austenite to proeutectoid ferrite at temperatures in the two phase region can be described by the Avrami equation $[X=1-$ $\left.\exp \left(-b t^{n}\right)\right]$. The results of the calculation for different grain sizes and the identical isothermal holding temperature are given in Table 2 .

A notable characteristic is due to the austenite grain size. There is a variation of the ferrite morphology at the end of the CCC test due to a change in the $\mathrm{Ar}_{3}$ temperature, which, in turn, is due to the change of the austenite grain size. This can be observed in the CCC curves of different austenite grain sizes (Fig. 2). As is indicated in this figure, the deviation which was related to acicular ferrite formation, has disappeared on changing the austenite grain size from 230 to $40 \mu \mathrm{m}$. It should be noted that, the higher flow stresses in the coarser austenite grain $(230 \mu \mathrm{m})$ can be related to grain boundary sliding, operating at high temperatures and low strain rates.

\subsection{Effect of Ferrite Volume Fraction}

To determine the effect of ferrite quantity on the amount of retained austenite, the specimen, after performing the basic TMP at higher temperatures (Fig. 1), was held at a temperature below the $\operatorname{Ar}_{3}\left(650^{\circ} \mathrm{C}\right)$ for various times, followed by quenching into the salt bath. All the specimens before air cooling to room temperature were held isothermally at $400^{\circ} \mathrm{C}$ in the salt bath for $2 \mathrm{~min}$. Figure 3 shows typical microstructures of steel A after 1 and $5 \mathrm{~min}$ holding at $650^{\circ} \mathrm{C}$, and illustrates increases in the ferrite quantity after the longer holding time. The variation of retained austenite quantity with the amount of ferrite for steels $\mathrm{A}$ and $\mathrm{B}$, for similar prior austenite

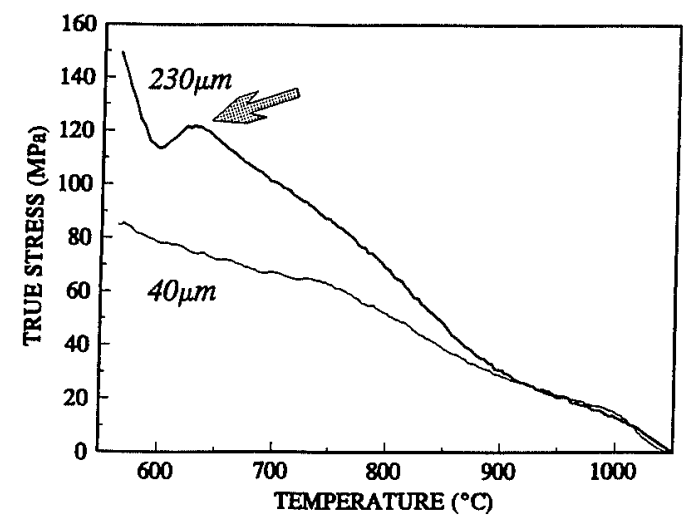

Fig. 2. The CCC true stress-temperature curves of steel A for two different prior austenite grain sizes. The arrow indicates the deviation which was related to the start of acicular ferrite formation. ${ }^{5)}$

Table 2. Variations of ferrite formation characteristics with prior austenite grain size.

\begin{tabular}{|c||c||c||c||c||c||c|}
\hline Steel & Grain Size $(\mu \mathrm{m})$ & $\boldsymbol{n}$ & $\boldsymbol{L n} \boldsymbol{b}$ & $\boldsymbol{A r}_{\mathbf{1}}\left({ }^{\circ} \mathrm{C}\right)$ & $\boldsymbol{A r}_{\boldsymbol{3}}\left({ }^{\circ} \mathbf{C}\right)$ & $\boldsymbol{T}_{\boldsymbol{n} \boldsymbol{r}}\left({ }^{\circ} \mathrm{C}\right)$ \\
\hline $\boldsymbol{A}$ & 230 & 1.359 & -9.674 & - & $755 \pm 5$ & - \\
\hline $\boldsymbol{A}$ & 70 & 1.804 & -11.100 & - & $775 \pm 5$ & - \\
\hline $\boldsymbol{A}$ & 40 & 0.870 & -5.250 & $590 \pm 5$ & $810 \pm 5$ & $930 \pm 5$ \\
\hline $\boldsymbol{B}$ & 80 & 1.971 & -11.114 & - & $780 \pm 5$ & - \\
\hline $\boldsymbol{B}$ & 45 & 1.117 & -5.678 & $630 \pm 5$ & $815 \pm 5$ & $910 \pm 5$ \\
\hline
\end{tabular}




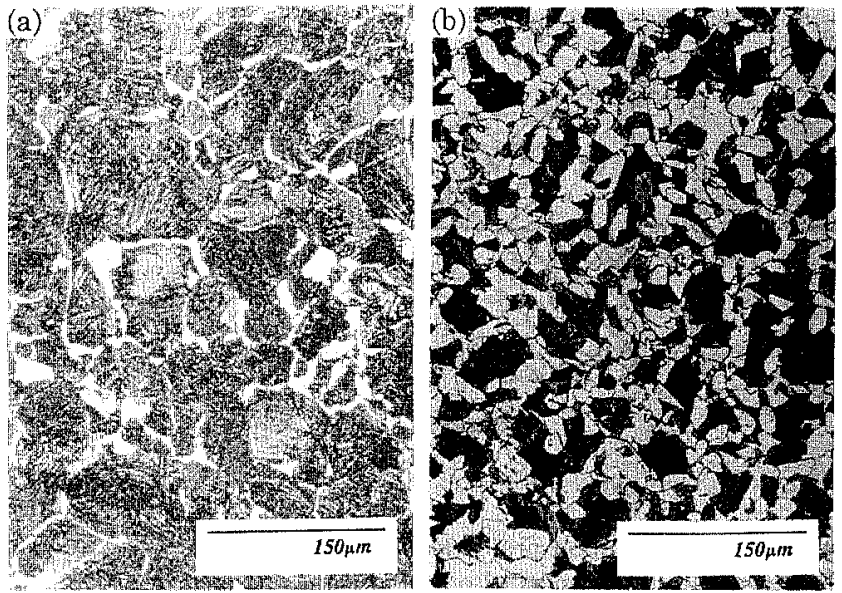

Fig. 3. Optical microstructure of steel A after, (a) 1 min and (b) $5 \mathrm{~min}$ holding at $650^{\circ} \mathrm{C}$.

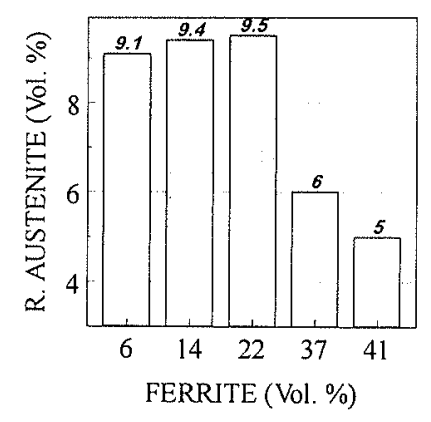

(a)

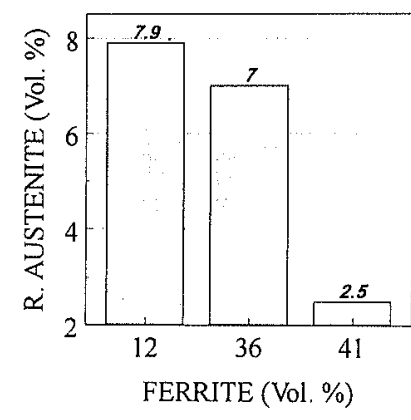

(b)
Fig. 4. Variation of the retained austenite volume fraction with the amount of ferrite; (a) steel $A$ with the prior austenite grain size of $40 \mu \mathrm{m}$ and (b) steel B with the prior austenite grain size of $45 \mu \mathrm{m}$.

grain sizes, is shown in Fig. 4. It seems that, there may be an optimum volume fraction of ferrite which maximises the amount of retained austenite, although for large amounts of ferrite, the retained austenite falls significantly.

Figures 4(a) and 5 show the effect of austenite grain size and ferrite volume fraction of steel $\mathrm{A}$ on the $V_{\mathrm{RA}}$ (retained austenite volume fraction). As can be seen, the existence of an optimum ferrite fraction which leads to a maximum amount of retained austenite appears to be repeated for all austenite grain sizes. Furthermore, it was observed that (Figs. 5(a) and 6), for an intermediate prior austenite grain size, the retained austenite volume fraction increased at much higher ferrite fraction (in this case $\sim 50 \%$ ).

The observed changes in the retained austenite characteristics (mainly volume fraction) with ferrite quantity and with the combined effects of prior austenite grain size and ferrite fraction (Figs. 4, 5 and 6), can be rationalized as follows. Generally, ferrite, which is the first transformation product of hot deformed austenite in this work, changes the morphology and composition of the remaining austenite (i.e. the austenite which remains after completing the transformation of the parent austenite-to-ferrite). It is these that affect the retained austenite characteristics.

From the point of view of geometrical configuration, the only way to stabilize the remaining austenite is by

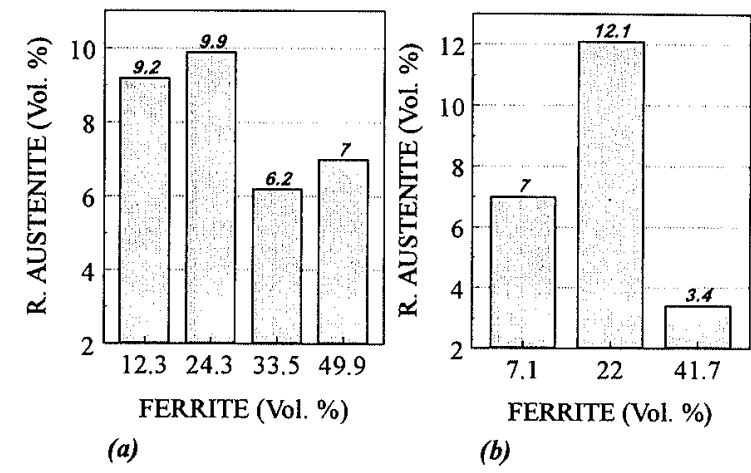

Fig. 5. Variation of the retained austenite volume fraction with the ferrite quantity of steel A for different prior austenite grain sizes; (a) $70 \mu \mathrm{m}$ and (b) $230 \mu \mathrm{m}$.

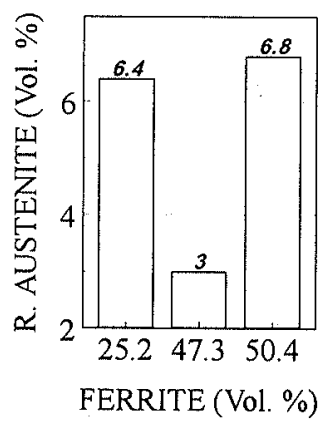

Fig. 6. Variation of the retained austenite volume fraction with the ferrite quantity of steel $B$ for the prior austenite grain size of $80 \mu \mathrm{m}$.

trapping the austenite through the impingement mechanism during growth of polygonal ferrite. The remaining austenite has a smaller particle size, thereby assisting in its stabilization. ${ }^{9)}$ Thus, in general, an increase in $V_{\text {RA }}$ would be expected with increasing ferrite quantity, and decreasing austenite grain size. However, these factors also influence the compositional variations in the remaining (untransformed) austenite during ferrite formation. This affects chemical stabilization of the austenite, and is considered in the following.

During the formation of ferrite, carbon diffuses in the austenite ahead of the $\alpha / \gamma$ interface. Figure 7(a) shows a portion of the $\mathrm{Fe}-\mathrm{Fe}_{3} \mathrm{C}$ diagram, and Fig. 7(b) shows a plot of carbon concentration normal to the $\alpha / \gamma$ boundaries. In this case, since equilibrium is assumed to be attained only at the $\alpha / \gamma$ interface, the carbon concentrations in $\alpha$ and $\gamma$ at this interface, denoted by $C_{\alpha}^{\alpha \gamma}$ and $C_{\gamma}^{\gamma \alpha}$, respectively, correspond to those of the equilibrium phase diagram. As can be seen, (Fig. 7(c)), by increasing the holding time or ferrite volume fraction at a given temperature, the remaining austenite becomes more homogeneous with respect to carbon. Note also that the average carbon concentration of the untransformed austenite is increased. The latter was confirmed by neutron diffraction results. ${ }^{10}$ )

Generally, there are three models concerning the growth process in $\mathrm{Fe}-\mathrm{C}-X$ alloys, where $X$ can be $\mathrm{Mn}$, $\mathrm{Si}, \mathrm{Ni}, \mathrm{Cr}$, etc. The models are largely similar, but are differentiated through the following assumptions, (i) the establishment of local equilibrium at $\alpha / \gamma$ boundaries with bulk partitioning of both $X$ and $\mathrm{C}$ between $\gamma$ and $\alpha$, (ii) 


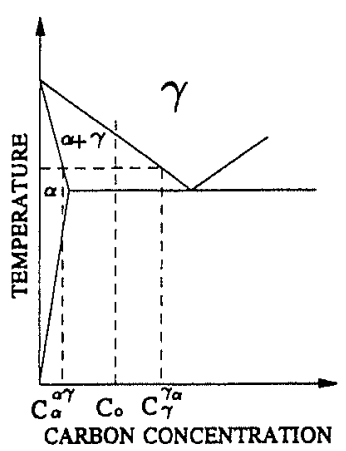

(a)

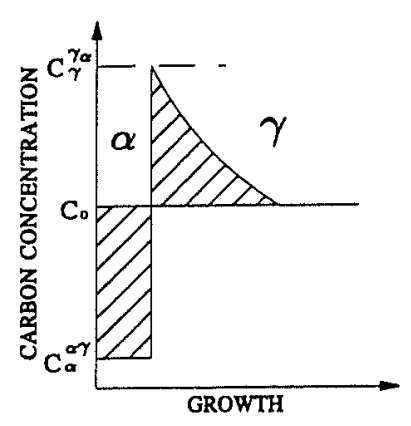

(b)

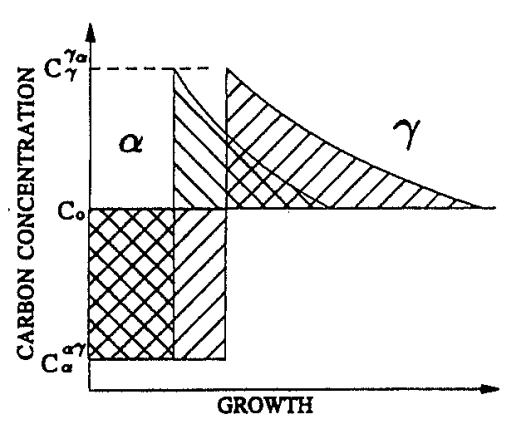

(c)

Fig. 7. (a) A portion of the $\mathrm{Fe}-\mathrm{Fe}_{3} \mathrm{C}$ phase diagram, (b) carbon concentration profile along a direction perpendicular to the austenite/ferrite interface, (c) carbon concentration profile in front of growing ferrite at different time intervals or different volume fractions of ferrite.

local equilibrium at $\alpha / \gamma$ interfaces with localized "pile-up" of $X$ in front of the advancing $\alpha / \gamma$ boundaries and (iii) paraequilibrium (the situation in which the substitutional alloying elements are unable to partition during the isothermal holding period) at $\alpha / \gamma$ boundaries, with partitioning of carbon only. The best overall agreement between experimental and calculated growth kinetics and compositional profile was reported with the paraequilibrium concept. ${ }^{11)}$ It should be reiterated that the operation of paraequilibrium growth conditions implies that the concentration of $X$ in ferrite is indistinguishable from that in austenite. If there is significant size misfit between $X$ atoms and $\mathrm{Fe}$ atoms, particularly in austenite but also in ferrite, $X$ atoms will accumulate in disordered areas of austenite-ferrite boundaries during growth (this is known as solute drag-like effect, SDLE). The "sweeping up" by-a-moving-boundary mechanism of $X$ segregation in the SDLE theory is one basic difference with respect to the familiar solute drag effect operative during grain growth and recrystallization, wherein $X$ atoms diffuse to a stationary boundary with volume diffusion-controlled kinetics.

Assuming the existence of paraequilibrium growth conditions, because of the short isothermal holding times used in this investigation, it is the carbon (at this stage) which is mostly dictating the stability of the remaining austenite; not the other alloying elements, such as $\mathrm{Mn}$. The carbon enrichment of austenite associated with the increase of ferrite volume fraction, via rejection of carbon into the remaining austenite, results in an increase of austenite stability against the subsequent transformations. This, in turn, would help to retain higher levels of the austenite at room temperature. Increasing the ferrite volume fraction beyond a certain level, however, appears to decrease the retained austenite volume fraction. From metallographical examinations, such as shown in Fig. 8, this can be related to either the shift of the pearlite C-curve to shorter times, or approaching the pearlite C-curve during the isothermal holding period in the corresponding TTT diagram (an increase in the chance of pearlite formation). In either case, pearlite would begin to form, thus, since pearlite consumes the carbon and reduces the stability of the remaining austenite, the volume fraction of retained austenite is lowered in this

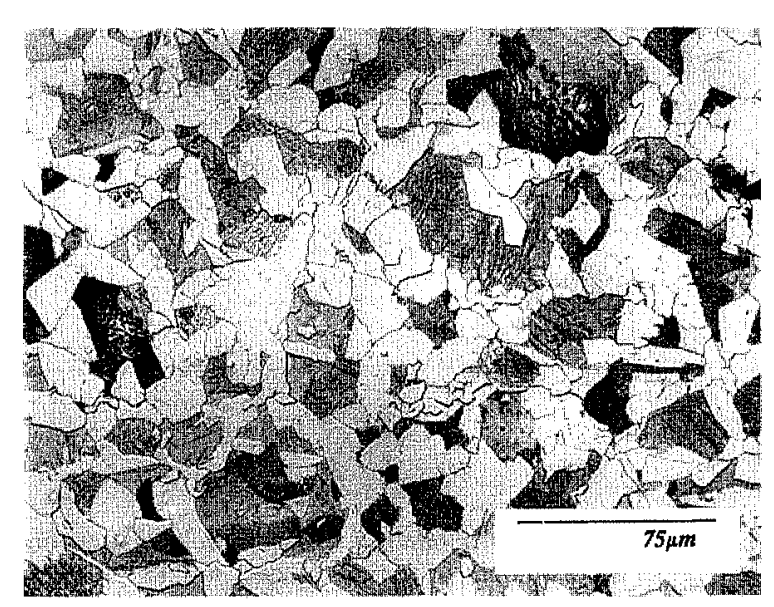

Fig. 8. The typical microstructures of steel A after long isothermal holding duration at $650^{\circ} \mathrm{C}$.

way.

As was illustrated in Figs. 5(a) and 6, a different behaviour of the retained austenite volume fraction with the amount of ferrite was found for an intermediate prior austenite grain size. Here, there was an increase of retained austenite volume fraction beyond a given large amount of ferrite (i.e. beyond a certain holding time) in the specimens of intermediate austenite grain size (Figs. 5(a) and 6), which can be rationalized as follows:

Since no microstructural changes (apart from ferrite quantity) were observed in the corresponding specimens during the intercritical treatment, another chemical stabilization factor (in addition to carbon) may be influencing the austenite retention. As is well established, ${ }^{12)}$ no partitioning of $X$ between austenite and ferrite occurred at any temperature from the $\mathrm{Ae}_{3}$ to the Ms temperature, when $X$ was $\mathrm{Si}, \mathrm{Mo}, \mathrm{Co}, \mathrm{Al}, \mathrm{Cr}$ and $\mathrm{Cu}$. This was a consequence of the paraequilibrium $\gamma /(\alpha+\gamma)$ boundary lying very close to the orthoequilibrium or actual equilibrium $\gamma /(\alpha+\gamma)$ boundary. Thus, the temperature range betwen these two boundaries was too small to permit sufficient undercooling to be achieved to allow formation of partitioned ferrite at detectable rates. In the case of $\mathrm{Mn}, \mathrm{Ni}$ and $\mathrm{Pt}$ alloying additions, however, partitioning was observed above a characteristic critical temperature, (Fig. 9). ${ }^{13)}$ As is well known, 
the partitioning of any alloying element depends on the diffusion characteristics. The latter is a function of temperature, time, concentration gradients and diffusion path and diffusion extent. These parameters could have resulted in partitioning of $\mathrm{Mn}$ to the remaining austenite, in the case of intermediate prior austenite grain size. Since $\mathrm{Mn}$ is an austenite stabilizer, the diffusional (e.g., pearlite) and martensitic transformations are both retarded, leading to a higher amount of the retained austenite for intermediate prior austenite grain size at the end of process. This means that the enrichment and homogenization of the remaining austenite with respect to $\mathrm{Mn}$, compensated for the effect of excess carbon of the remaining austenite, avoiding pearlite formation in the specimens with higher amounts of ferrite (as was observed for the other prior austenite grain sizes).

\subsection{Effect of Ferrite Grain Size}

Austenite pancaking is one of the methods used to

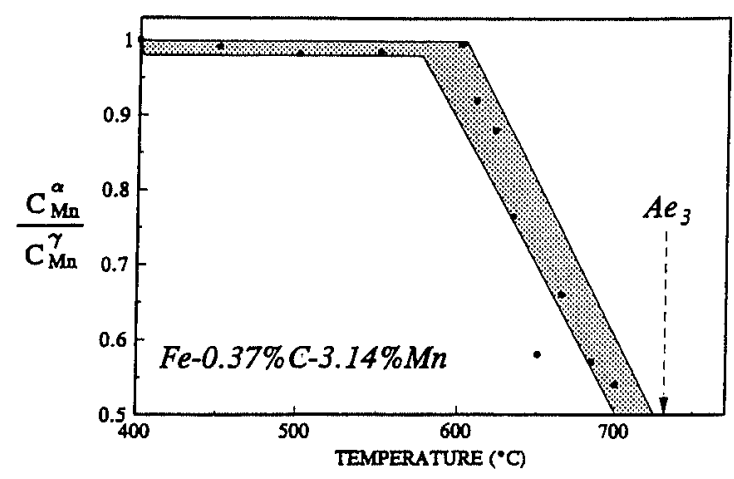

Fig. 9. Ratio of atom fraction $\mathrm{Mn}$ in ferrite to that in austenite for ferrite allotriomorphs.
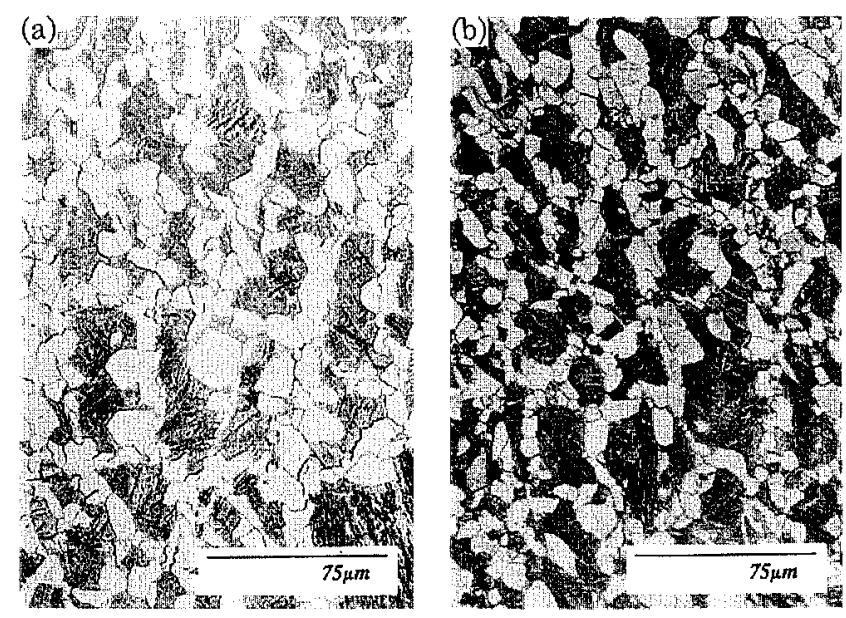

Fig. 10. Typical microstructures in steel A after, (a) $20 \%$ and (b) $30 \%$ strain in the no recrystallization region. refine the ferrite grain size in TMP. The latter is due to the additional ferrite nucleation sites, such as austenite grain boundary serrations, deformation bands and twins. As shown in Table 2, the $T_{\mathrm{nr}}$ 's for grades A and B were estimated to be about 930 and $910^{\circ} \mathrm{C}$, respectively. The effect of 20 and $30 \%$ strains in the no-recrystallization range on the microstructure of steel A is shown in Fig. 10. As can be seen, the increase of the strain from 20 to $30 \%$ resulted in ferrite grain refinement. Table 3 , for steel $A$, shows that a decrease in the ferrite grain size by pancaking does not increase the retained austenite quantity, contrary to the conclusions of Kawano et al. ${ }^{14,15)}$

Another way of refining the ferrite grain size is straining the specimen during transformation (dynamic transformation of austenite-to-ferrite). In this way, not only the ferrite grains can be refined, but a higher dislocation density (finer subgrain size) is established in the ferrite. To carry out the dynamic transformation, the specimen was deformed isothermally at a temperature below the $\mathrm{Ar}_{3}$ (i.e. in the two phase region). The effect of this process on the final microstructural components is tabulated in Table 3. As can be seen, the deformation during transformation not only has more effect on the ferrite grain refinement (Fig. 11), but retains more retained austenite compared to pancaking.

To summarize, ferrite refinement by the two different approaches, results in the following differences: (i) via pancaking, the result is a decrease in the retained austenite volume fraction; (ii) via dynamic transformation, the $V_{\mathrm{RA}}$ is somewhat increased. The latter supports the findings of Kawano et al. ${ }^{14,15)}$ Their explanation was that ferrite grain refinement increases the total area of the austenite/ferrite interface. This, in turn, increases the rate of carbon and $\mathrm{Mn}$ diffusion during the ferrite growth,
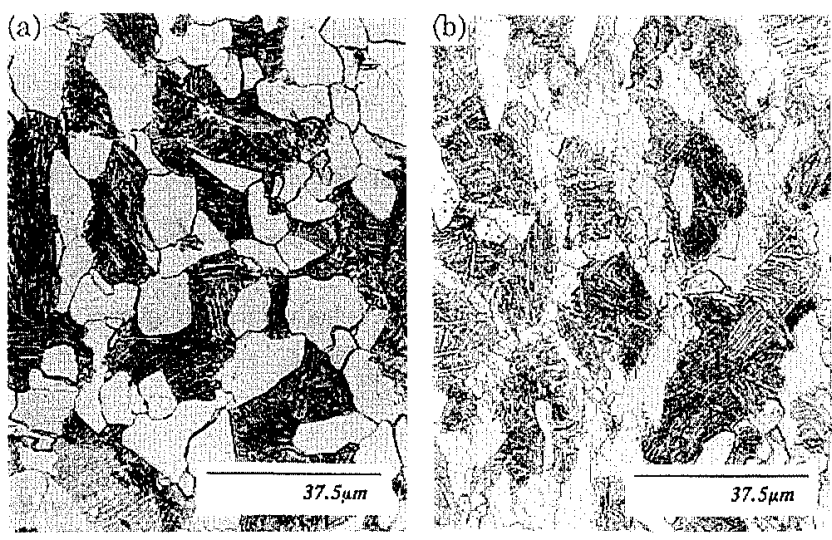

Fig. 11. Typical microstructures in steel $\mathrm{A}$ after, (a) $20 \%$ strain in no recrystallization region and (b) $20 \%$ strain during austenite-to-ferrite transformation.

Table 3. Variation of the $V_{\mathrm{RA}}$ with polygonal ferrite grain size obtained by different TMP schedules.

\begin{tabular}{|c|c|c|c|}
\hline Strain in the No Rex Region & $20 \%$ & $30 \%$ & - \\
\hline Strain during y-to- $\alpha$ Transformation & - & - & $20 \%$ \\
\hline Ferrite Volume Fraction & $27.5 \%$ & $30.0 \%$ & $25.0 \%$ \\
\hline Ferrite Grain Size & $19 \mu \mathrm{m}$ & $13 \mu \mathrm{m}$ & $10 \mu \mathrm{m}$ \\
\hline Retained Austenite Volume Fraction & $9.11 \%$ & $7.92 \%$ & $9.60 \%$ \\
\hline
\end{tabular}


thus leading to faster partitioning of alloying elements. However their work was based on a recrystallized austenite. In both present cases, dislocation densities during transformation will be higher.

In the case of pancaking, the transformation rate is increased. Thus, a given ferrite volume fraction is formed in a shorter periods, offsetting the increased rate of $\mathrm{C}$ and $\mathrm{Mn}$ diffusion. However, by straining in the two phase region (during transformation) the rate of transformation is much increased, thereby decreasing the ferrite grain size more significantly than pancaking. It also introduces dislocations in the ferrite, increasing the rate of diffusion and thus accelerating $\mathrm{C}$ and $\mathrm{Mn}$ partitioning into the remaining austenite. Since the deformation during the austenite-to-ferrite transformation is distributed between ferrite and austenite (although it is mostly concentrated in ferrite), the remaining austenite has a less dense substructure for the same amount of straining in the no recrystallization region. The austenite remaining after dynamic transformation is therefore less likely to form pearlite compared to pancaked austenite. In conclusion, although the effects of dynamic transformation and the ferrite grain size refinement on the retained austenite volume fraction are consistent with the results of Kawano et al., the mechanisms differ.

\subsection{Effect of Ferrite Morphology}

From the different morphologies of ferrite, two different categories can be distinguished. The first is characterised by a transformation without any surface re-

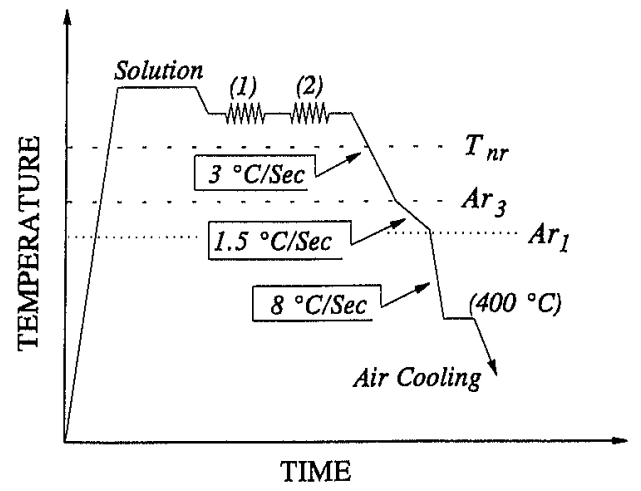

Fig. 12. The heat and deformation schedule used to generate acicular ferrite. lief effects and, consequently, leads to lower dislocation densities at the end of transformation, e.g. polygonal ferrite. The other type exhibits surface relief and higher densities of dislocations, e.g. acicular and Widmanstätten ferrite. ${ }^{16)}$ To generate acicular ferrite in addition to polygonal ferrite, the thermal and deformation schedule shown in Fig. 12 was applied, (this schedule was based on the $\mathrm{CCC}$ results). Here, the isothermal hold in the two phase region and the quench in the salt bath stages were substituted by continuous cooling in the furnace (in the two phase region) and with compressed air and argon (from the two phase region to the bainite hold temperature), respectively. The presence of the acicular ferrite in the microstructure after this treatment is seen in Fig. 13 for steels A and B.

Figure 14 shows the microstructural components in samples with and without acicular ferrite for steels $\mathrm{A}$ and $B$. As can be seen, the presence of acicular ferrite in steel $\mathrm{A}$ has resulted in a significant increase in the quantity of retained austenite. The opposite is, however, observed in steel B. Further in both steels, the retained austenite is mostly enclosed by fine acicular ferrite or coarse granular bainite ${ }^{17)}$ Essentially, the prior austenite grains have been fragmented by these phases, and the distributions of the white components are dictated by this grain fragmentation. Therefore, these smaller particles of austenite tend to be retained through the geometric effect.
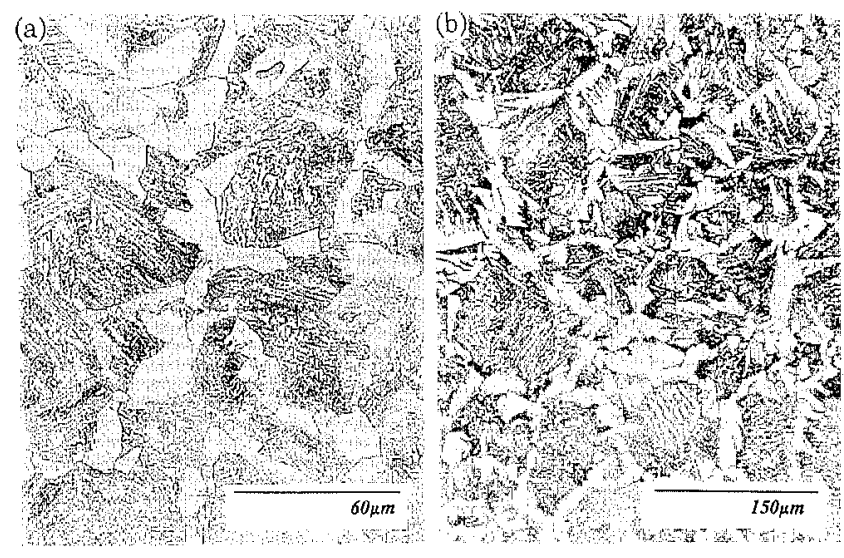

Fig. 13. Typical microstructures of (a) steel A and (b) steel B, revealing acicular ferrite.

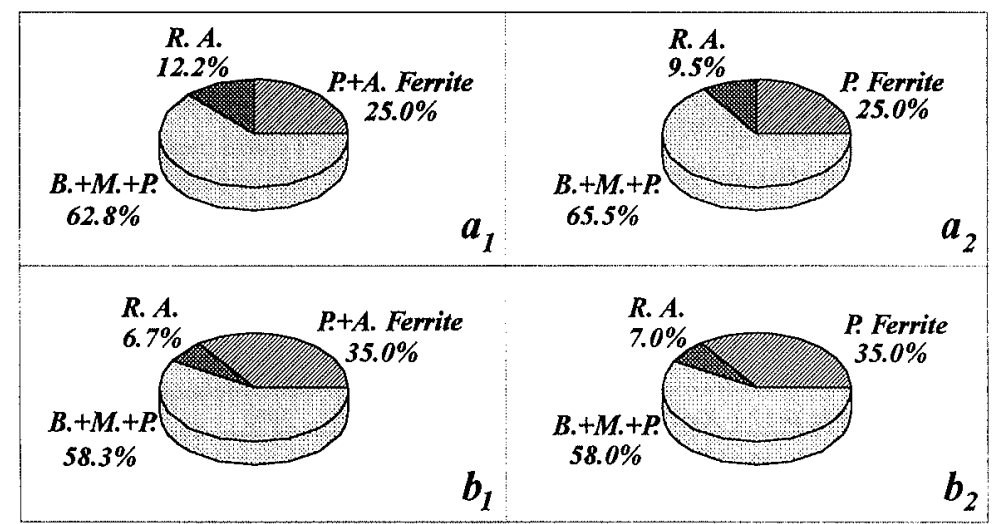

Fig. 14. The microstructural components of, $\left(a_{1}\right.$ and $\left.a_{2}\right)$ steel $A$ with and without acicular ferrite, respectively, and $\left(b_{1}\right.$ and $b_{2}$ ) steel $B$ with and without acicular ferrite, respectively. 
The response of steel $\mathrm{A}$, i.e., the increase of the retained austenite volume fraction, to the parent austenite fragmentation by acicular ferrite, therefore, follows the above rationale. The results of steel $\mathrm{B}$ are contradictory because of the presence of pearlite in its microstructure. Since the pearlite transformation start temperature of steel $B$ is higher than that of steel $A$, the same procedure (continues cooling through the two phase region, Fig. 12) to obtain acicular ferrite resulted in pearlite formation in steel B. This decreased the carbon in the remaining austenite, leading to a reduction in the retained austenite volume fraction.

\section{Conclusions}

By increasing the amount of ferrite, the retained austenite volume fraction, after a slight plateau, decreases. Furthermore, for all austenite grain sizes, it appears that there is an optimum amount of ferrite which maximises the amount of retained austenite. An increase of the $V_{\mathrm{RA}}$ beyond a certain ferrite fraction occurs for an intermediate austenite grain size. This behaviour also takes place in steel $\mathrm{B}$ but for a different ferrite fraction.

The results of this work show that a decrease in the ferrite grain size by pancaking does not increase the retained austenite quantity. On the other hand, deformation during dynamic transformation not only has more effect on ferrite grain refinement, but increases the retained austenite volume fraction.

The presence of acicular ferrite in steel A resulted in a significant increase in the quantity of retained austenite. Further, in both steels, the martensite/retained austenite phases are mostly enclosed by fine acicular ferrite or coarse granular bainite. Essentially, the prior austenite grains have been fragmented by these phases, and the distributions of these phases are dictated by this grain fragmentation. The effect of acicular ferrite is much greater than that of pancaking and dynamic transformation.

\section{Acknowledgments}

The financial support of the Canadian Steel Industry
Research Association and the Natural Sciences and Engineering Research Council of Canada is gratefully acknowledged. A. Zarei-Hanzaki is also grateful to Tehran University for their support.

\section{REFERENCES}

1) I. Tsukatani, S. Hashimoto and T. Inoue: ISIJ Int., 31 (1991), 992.

2) V. F. Zackay, E. R. Parker, D. Fahr and R. Bush: Trans. Am. Soc. Mat., 60 (1967), 252.

3) A. K. Sinha: Ferrous Physical Metallurgy, Butterworths, London, (1989), 324.

4) A. Zarei-Hanzaki, P. D. Hodgson and S. Yue: 33rd Mechanical Working and Steel Processing Conf., Iron and Steel Society of AIME, XXIX, St. Louis, (1992), 459.

5) A. Zarei-Hanzaki, R. Pandi, P. D. Hodgson and S. Yue: Metall. Trans., 24A (1993), 2657.

6) Y. Sakuma, S. Matsumura and H. Takechi: Metall. Trans., 22A (1991), 489.

7) B. D. Cullity: Elements of X-Ray Diffraction, Second Ed., Addison-Wesley Publishing Company, Inc., Mass., (1978).

8) C. F. Jatczak, J. A. Larson and S. W. Shin: Retained Austenite and Its Measurements by X-ray Diffraction, Society of Automotive Engineers, Inc., Warrendale, PA, (1980), 9.

9) J. M. Rigsbee: ICOMAT 1979, Martensitic Transformations, Cambridge, Mass, (1979), 381.

10) A. Zarei-Hanzaki, J. Root, P. D. Hodgson and S. Yue: Acta Metall, 43 (1995), No. 2, 569.

11) J. R. Bradley and H. I. Aaronson: Metall. Trans., 12A (1981), 1729.

12) W. T. Reynolds, Jr., M. Enomoto and H. I. Aaronson: Phase Transformations in Ferrous Alloys, Conf. Proc., AIME, Warrendale, Penn., (1983), 155.

13) H. I. Aaronson and H. A. Domian: Trans. TMS-AIME, 236 (1966), 768.

14) O. Kawano, M. Takahashi, J. Wakita, K. Esaka and H. Abe: Proc. Int. Conf. on Physical Metallurgy of Thermomechanical Processing of Steel and Other Metals, (THERMEC-88), ed. by I. Tamura, Tokyo, Japan, (1988), 692.

15) O. Kawano, J. Haji, J. Wakita and K. Esaka: Microstructural Evolution in Metal Processing, American Society of Mechanical Engineers, New York, (1990), 11

16) H. K. D. H. Bhadeshia: Prog. Mater. Sci., 29 (1985), 321.

17) A. Zarei-Hanzaki: Ph. D. Thesis, McGill University, (1994). 